\title{
EMPLOYMENT OF IGBT-TRANSISTORS FOR BIPOLAR IMPULSED MICRO-ARC OXIDATION
}

\author{
Alexander Krainyukov ${ }^{1}$, Valery Kutev ${ }^{2}$ \\ Telematics and Logistics Institute, \\ Lomonosova street 1, Riga, LV-1019, Latvia \\ Phone:+371 67100634, fax: +37167100660 \\ E-mail: ${ }^{1}$ Krainukovs.A@tsi.lv, ${ }^{2}$ Kutevs.V@tsi.lv
}

\begin{abstract}
The paper is devoted to the use of insulated gate bipolar transistors (IGBT) for the micro-arc oxidation (MAO) process. The technical requirements to the current switches of power supplies for the pulsed bipolar MAO technology have been developed. The research installation for investigating the IGBT commutation processes during the pulse anode-cathode oxidation has been constructed. The experiments have been performed with its help in order to estimate the possibility of using half-bridge IGBT-modules with different drivers. The research results of the commutation processes investigation for different IGBT half- bridge modules are presented.
\end{abstract}

Keywords: micro-arc oxidation, insulated gate bipolar transistors, high voltage, commutation process, ballast resistance

\section{Introduction}

The structural components of different transport devices and systems operate under the conditions of stress - corrosion fracture under the impact of various aggressive factors. For example, the cylinderpiston group of aircraft and automobile engines, turbine blades and nozzle propellers are subjected to high temperature gas erosion. The operating conditions and the increasing performance requirements for technical devices put forward the especially high demand for the structural materials. The materials of the structural components should have a high strength, corrosion resistance, low specific gravity and also withstand considerable thermal stress. The micro arc oxidation (MAO) is widely used to obtain the necessary characteristics of the gate metals group ( $\mathrm{Al}, \mathrm{Mg}, \mathrm{Ti}, \mathrm{Zr}, \mathrm{Nb}, \mathrm{Ta}$, etc.), which is an electrochemical process of oxidation of the surface of metals and their alloys in electrolytic plasma for the purpose of obtaining oxide coatings (Suminov et al.2011).

The structure and composition of MAO coatings depend on the base material, the composition of the electrolyte and the conditions of their formation. The mode of operation, technical parameters and circuit design of the sources of technological current and devices for controlling these sources are important factors. There are many implementations of MAO plants and devices of technological current sources, which are used for performing research and practical tasks of MAO.

Nevertheless, the current regulators used for MAO have low functional opportunities; this fact in its turn restricts the set of properties of the formed MAO coatings. Low functionality of the used current regulators is conditioned by the use of outdated component base (capacitor, thyristor, thyristor-capacitor current regulators) (Suminov et al.2005).

The IGBT transistors (Insulated Gate Bipolar Transistor) have currently become the key components in power electronic devices. The IGBT - transistors provide switching currents up to several kilo-amperes at the reverse voltages of several kilovolts (Martynenko et al.2004). The technology of micro-arc oxidation assumes switching of currents greater than $100 \mathrm{~A}$ at voltages close to $1000 \mathrm{~V}$. The improved functionality of technological current sources (current regulators) for MAO is possible on the basis of modern electronic components of power electronics of IGBT transistors.

\section{Requirements for the Technological Current Sources (Current Regulators) of MAO}

The electric mode of generating MAO-coatings determines their physical properties at high degree: hardness, porosity, roughness and wear resistance, etc. Using the impulse mode of MAO allows improving the physical characteristics of MAO coatings. The most effective electric modes of the MAO process are achieved with the use of the high-current impulse anode-cathode (AC) polarization, including the usage of periodic anode (A) and cathode (C) polarization with no-current pause. The results of these studies indicate the results as follows (Suminov et al.2005):

1) the change of the total current density correlates with the speed of the oxide layer formation;

2) there exists the maximal thicknesses of the obtained micro-arc coating at A and AC modes; 
3) the growth rate and maximum thickness of micro-arc coatings increase with the increase of the current ratio $i_{K} / i_{a}$;

4) the maximum thickness of the micro-arc coating increases significantly during the transition from the MAO process in $\mathrm{AC}$ mode, at $\mathrm{i}_{\mathrm{K}} / \mathrm{i}_{\mathrm{a}}=1$ to the combined electric mode: $\mathrm{AC}-\mathrm{AC}-\ldots-\mathrm{C}-\mathrm{AC}$;

5) impulse $\mathrm{A}, \mathrm{C}, \mathrm{AC}$ modes of micro-arc coatings are performed at the following technical parameters:

- the range of impulse repetition frequencies from 0 to $2000 \mathrm{~Hz}$;

- the maximum values of currents are hundreds of Amperes;

- the maximum voltage values are hundreds of Volts.

Thus, the functionality of the current controller determines the set of possible electrical modes and, accordingly, the range of properties of the formed coatings. To perform impulse A, C and AC modes of the micro-arc oxidation, the current regulators must ensure the formation of anodic, cathodic and anodic / cathodic pulses with a frequency rate in the range from 0 to $2000 \mathrm{~Hz}$, with current from 0 to $200 \mathrm{~A}$, with a voltage from $0 . .550 \mathrm{~V}$, and they also should allow controlling the impulse duration and the duration of the no-current pause.

There are two mechanisms of formation of coatings at the procedure of the micro-arc oxidation: mechanism of anodic oxidation and the mechanism of plasma-chemical reactions. Correspondently, the total current consists of the anodizing current and the current of the micro-arc discharges. The magnitude of the current flowing through the oxidised layers is modified; this means that the resistance of the oxidised layers is also changed, i.e. the oxidised layers are characterized by a resistance varying with time.

A circuit segment "anode - oxidised layer - electrolyte - cathode - lead wires" is the load for the switch components of the current regulators of MAO. The equivalent electric circuit of this circuit segment is shown in Fig. 1 (Gordienko et al.2013).

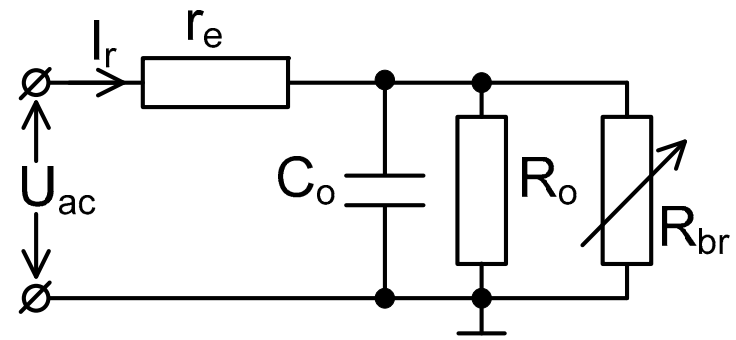

Figure 1. Equivalent electric circuit diagram of the segment "anode - oxidized layer - electrolyte - cathode"

There are the following designations of the components for Fig. 1:

- $r_{e}$ is the resistance of the electrolyte;

- $\mathrm{C}_{\mathrm{o}}$ is the capacitance of the oxide layer;

- $\mathrm{R}_{\mathrm{o}}$ is the electric resistance of the oxide layer;

- $\mathrm{R}_{\mathrm{br}}$ is the nonlinear resistance of the thermal breakdown zone;

- $\mathrm{U}_{\mathrm{ac}}$ is the voltage of the electrochemical cell (between the anode and the cathode);

- $\mathrm{I}_{\mathrm{r}}$ is the output current of the current controller.

The total current of the power supply controller at the MAO consists of the anodizing current flowing through the oxide layer (via $R_{o}$ and $C_{o}$ ) and current of the micro-arc discharges flowing through $R_{b r}$. The magnitude of the current flowing through the zone of the micro arc discharge changes, since there changes the resistance of the thermal no-current pause zone.

Analysis of the electric modes for the MAO process has allowed formulation of the functional requirements to the current regulator, ensuring the formation of coatings with a wide range of specified properties:

- ensuring unipolar and bipolar asymmetric impulse output currents;

- individual specifying of the levels of anodic and cathodic currents;

- individual specifying of the durations of the voltage impulses action and their repetition frequency;

- restricting the amplitude of the output voltage;

- control of the maximum load current.

\section{Experimental Installation for the Study of the Switching Processes of IGBT Transistors}

The IGBT - transistors have the advantages of easy control over the MOSFET (minimum energy cost of the control) and low conduction losses, typical for bipolar transistors. Due to these advantages, the properties of IGBT - transistors are close to the properties of the "ideal" electronic key. 
Modern IGBT modules are the most powerful and completely controllable semiconductor switches. The IGBT-modules drivers are used to control the IGBT-modules. The IGBT modules drivers are complex complete devices providing the power amplification of the control impulses and the protection of IGBT-transistors and various types of protection of IGBT transistors, including protection against short circuit or over-current.

The experimental installation which a block-diagram shown in Fig.2 has been developed for the study of commutation processes of the IGBT transistors at performing MAO. The experimental installation has been developed taking into account the peculiarities of the process of micro-arc oxidation and the characteristics of the IGBT transistors operation as current regulators.

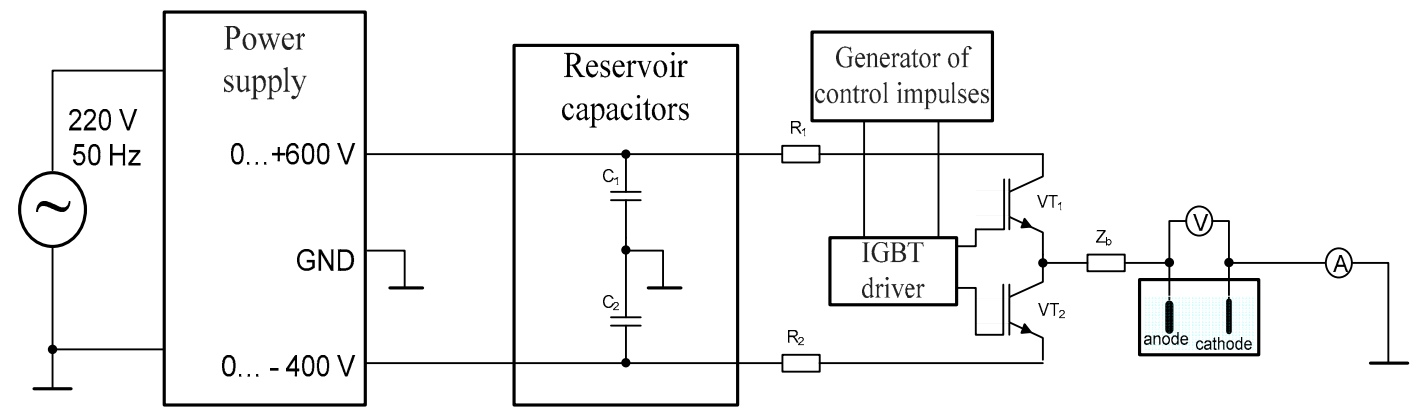

Figure 2. Block- diagram of the experimental installation

The experimental installation includes: power supply, reservoir capacitor unit, current limiting resistors $\mathrm{R}_{0}$ and $\mathrm{R}_{2}$, the generator of control impulses, the IGBT driver, the IGBT module, the IGBT modules load ("anode - cathode") and complex ballast resistance $Z_{b}$.

The experimental installation uses:

- half-bridge circuit of the current regulator, made on IGBT transistors;

- the IGBT driver controlling the operation of IGBT transistors, to ensure the maximum utilization ratio of the IGBT transistors and protection of the transistors from overload.

Voltage of the power source charges the reservoir capacitors, which are discharged through the circuit "current limiting resistor - the segment "collector-emitter" of the IGBT transistor - the load instrument shunt". The control impulses, the power of which is provided by the IGBT driver, are given to the transistors gates for opening the IGBT transistors. The repetition frequency and the duration of the control impulses are set by the impulse generator.

The functional elements of the experimental set have the following technical properties:

1. Power supply: bipolar adjustable voltage source, the range of the positive voltage is $0 . .+600 \mathrm{~V}$, the range of negative voltages is $0-400 \mathrm{~V}$. The maximum current: the source of positive voltage $-4 \mathrm{~A}$, negative $-6 \mathrm{~A}$. Input voltage primarily $220 \mathrm{~V}, 50 \mathrm{~Hz}$. Assured isolation voltage from the electric grid is $3 \mathrm{kV}$.

2. Block of reservoir capacitors: four capacitor of $160 \mu \mathrm{F}$. The no-current pause voltage is $1200 \mathrm{~V}$. The Maximum discharge current is $200 \mathrm{~A}$.

3. The impulse generator generates the control impulses: the rectangular impulses with a given duration and the impulse repetition period on three outputs (channels). The duration and the impulse repetition period of the output signals are set equal for simultaneously all channels. However, the impulses of the additional channels are generated with a delay relative to the main channel impulses, and the delay time can be set equal from zero to the length of the pause between impulses. The height of the impulses at the outputs of the generator channels is equal to $5 \mathrm{~V}$. This principle of generating the control impulses on the primary and secondary channels allows performing the impulse AC mode of MAO.

The experimental set allows the connection of measuring devices for monitoring the switching processes and the measurement of parameters and characteristics of the IGBT transistors and IGBT driver.

The IGBT module Infineon IGBT FF 200R17CE4 G1338 has been used for the study of the switching process. The IGBT module FF 200R17CE4 contains the upper and the lower IGBT transistors, forming a half-bridge circuit. The IGBT module FF 200R17CE4 has the following limiting electrical parameters: the maximum voltage collector - emitter is $1700 \mathrm{~V}$ (at $25^{\circ} \mathrm{C}$ ); the maximum collector current is $200 \mathrm{~A}$ (at $25^{\circ} \mathrm{C}$ ), allowing employment of it for executing MAO processes.

The drivers of the IGBT modules of different firms have been used to control the switches of the IGBT modules (Nikitin, 2010): Dual SCALE Driver 2 SD 315 AI, POWERCON MITSUBISHI HYBRID ICs M57962L, SCHI 10/17R, SCYPER 32, 2SD106AI Dual SCALE Driver Core. The results of investigating the listed drivers of power IGBT modules at MAO show that these drivers:

1) have slow response at IGBT transistor turning on and off;

2) do not allow a rapid and flexible change in the circuit parameters of the control and protection of the IGBT transistor; 
3) do not secure the protection of the IGBT transistor from reconnection in case of tripping the current protection.

These features of the investigated drivers do not allow using them in the systems used for MAO processes. By the results of the researches, it has been determined that the driver of the IGBT transistors used for MAO shall provide the following functions:

- performance at the edge and the slice of the PWM signal is not more than $100 \mathrm{~ns}$;

- protection of the transistor at current, varying over a wide range of values;

- protection of the transistor from reconnection in case of tripping the current protection;

- galvanic isolation on all controlling circuit;

- high noise immunity.

Considering these requirements, a dual-channel IGBT driver transistor with bipolar controlling impulses has been developed. The main peculiarity of the developed driver is the fact that it provides high performance of the protection circuits of the IGBT transistor by means of circuit designs and selection of electronic components, and there is possibility to set up these circuits flexibly and quickly. The developed dual-channel driver has the following options:

- maximum controlled voltage collector-emitter $-1700 \mathrm{~V}$;

- output voltage is $+15 \mathrm{~V}$;

- maximum output current is $+18 \mathrm{~A}$;

- switching frequency is $100 \mathrm{kHz}$;

- insulation voltage is $4 \mathrm{kV}$;

- the slew rate / coefficient of voltage increase is $100 \mathrm{kV} / \mu \mathrm{s}$;

- the turn-on delay time is $100 \mathrm{~ns}$;

- the turn-off delay time is $100 \mathrm{~ns}$;

- blocking time after emergency (overload) - 1 sec. transistors.

The integrated ballast resistance is used to reduce the current in the output circuit of the IGBT

\section{Results of the Study of the Switching Process at the IGBT-Transistor Operation on the Oxidized Detail Immersed in the Electrolyte}

The oxidation bath, shown in Fig. 3 was made for this research; it was filled with electrolyte. The bath is made of chemically resistant plastic material: vinyl plastic. The dimensions of the bath are $440 \mathrm{~mm}$ x $240 \mathrm{~mm}$ x $300 \mathrm{~mm}$. The thickness of the walls is $50 \mathrm{~mm}$.

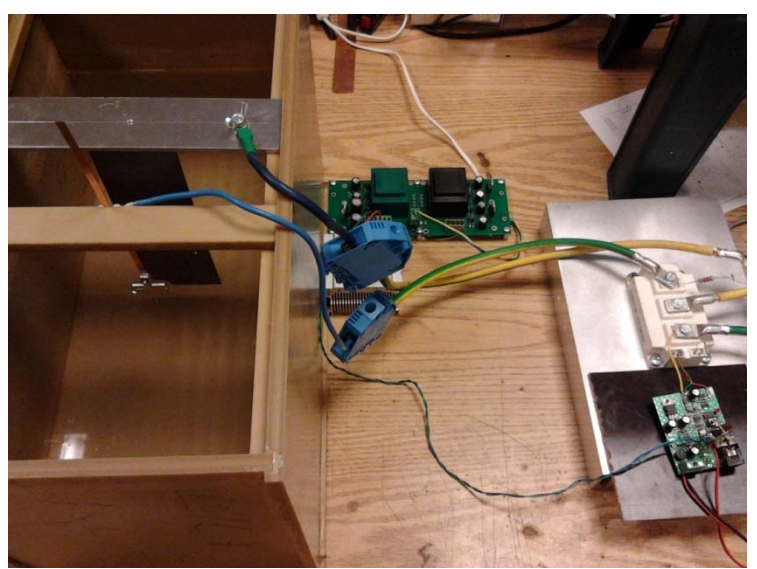

Figure 3. Experimental block of MAO

The micro-arc oxidation of aluminum specimens of size of 20x20mm was performed at the research. The samples were subjected to anodization before performing micro-arc oxidation; anodization was carried out in two stages. At the first stage the anodizing was performed in a solution of $\mathrm{CrO} 3+\mathrm{H} 3 \mathrm{PO} 4$, and at the second phase the plates were placed in a $15 \%$ solution of oxalic acid. As a result of anodizing the insulating layer was created on the surface of aluminum plates.

To conduct micro-arc oxidation, the emitter of the IGBT transistor was connected to the anode (aluminum plates), and the cathode was connected to the general wire in accordance with the structural scheme of the experimental block (Fig. 3).

During the experiment the changes of voltage and current on the section of the anode - cathode of the experimental block MAO were investigated (metal of the oxidized plate - oxidized layer of the detail - 
electrolyte - stainless steel plate) in impulse AC mode of MAO. The parameters of MAO: height of positive impulse is $400 \mathrm{~V}$, the height of the negative impulse is $200 \mathrm{~V}$, the impulse duration is $0.5 \mathrm{~s}$, the pause length between impulses is $0.5 \mathrm{~s}$, the impulse repetition period is $0.5 \mathrm{~Hz}$.

Since the oxidized layer is characterized by the capacity of $\mathrm{C}_{\text {сл }}$ (Fig.1), and the resistance of the electrolyte $r_{0}$ is insignificant, then the currents can exceed the maximum values at switching. The limit for the currents of the IGBT-transistors is provided by a ballast resistance of $Z_{\sigma}$. Six variants of inductiveresistive two-poles have been used as ballast resistance in our experiments. Five of them include resistive two-poles with inductor L1 connected with resistor R1 in parallel. The following parameters of inductor and resistor have been used in these connections: variant $1-\mathrm{L} 1=155 \mu \mathrm{H}, \mathrm{R} 1=13.7 \mathrm{Ohm}$; variant 2 $\mathrm{L} 1=446 \mu \mathrm{H}, \mathrm{R} 1=6.0 \mathrm{Ohm}$; variant $3-\mathrm{L} 1=950 \mu \mathrm{H}, \mathrm{R} 1=0,13 \mathrm{Ohm}$; variant $4-\mathrm{L} 1=1,0 \mathrm{mH}, \mathrm{R} 1=30.0 \mathrm{Ohm}$, variant $5-\mathrm{L} 1=2,5 \mathrm{mH}, \mathrm{R} 1=0,35 \mathrm{Ohm}$. For the sixth variant we used two resistive-inductance sequential two-poles with R1,L1 and R2,L2 which were connected in parallel. The following parameters of sequential circuits were used: $\mathrm{L} 1=2,5 \mathrm{mH}, \mathrm{R} 1=0.35 \mathrm{Ohm}, \mathrm{L} 2=0,53 \mathrm{mH}, \mathrm{R} 2=16.2 \mathrm{Ohm}$.
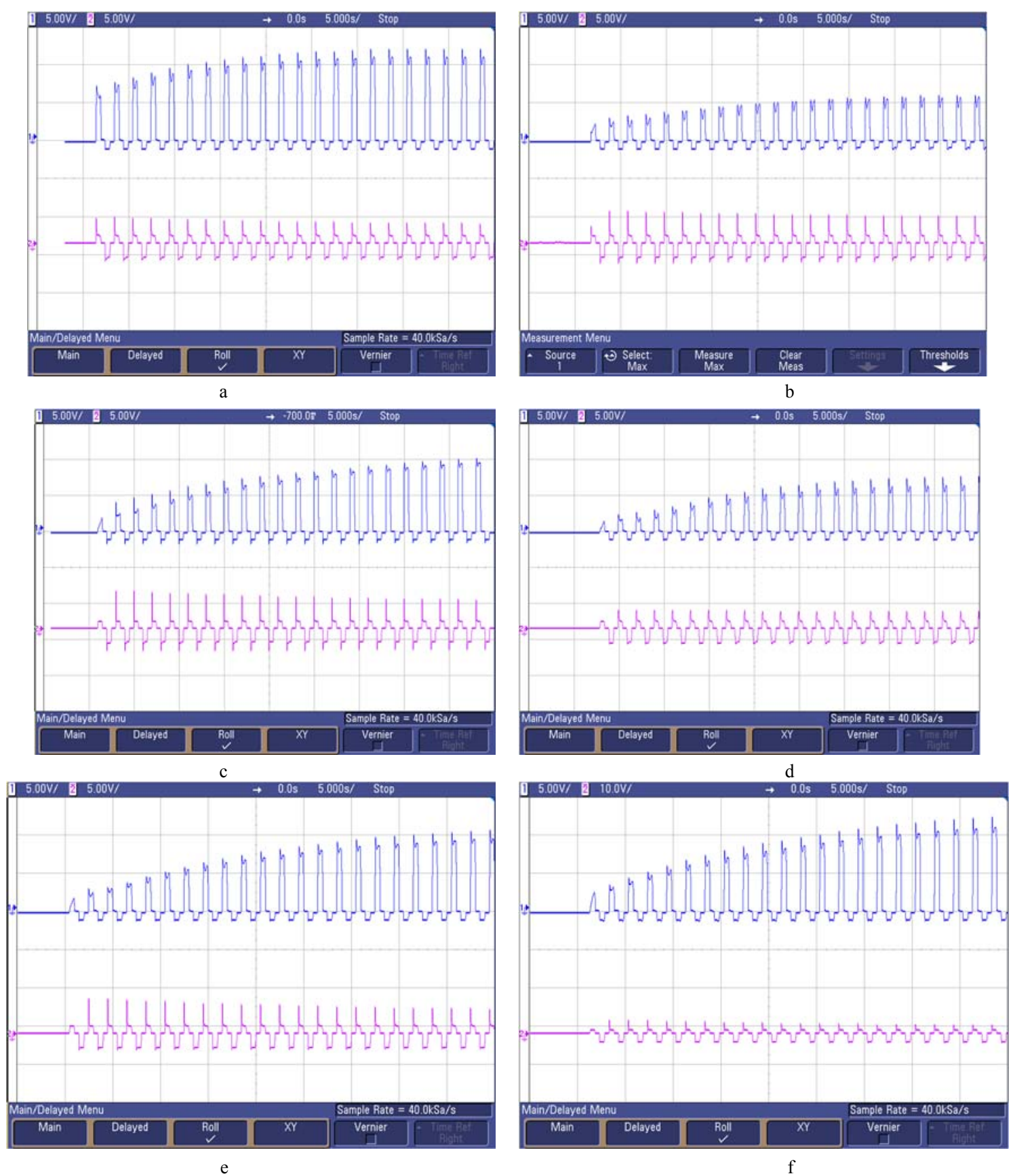

Figure 4. Time diagrams of voltages and currents on the section "anode - cathode" of the experimental block MAO at using different variants of ballast resistance: a - variant 1 ; b - variant 2 ; c - variant 3 ; d - variant 4 ; e - variant 5 ; f - variant 6 
In Fig. 4 the time diagrams of the voltages on the section "anode - cathode"( purple color), and the current at this segment (blue color) are shown. The oscillograms were obtained at using for each of variants the resistive two-pole connection.

Analysis of the current and voltage time diagrams, which are shown in Fig. 4, allows drawing the following conclusions:

1. The duration of the transition process MAO is about 40s. During this time, the resistance of the oxidized layer reaches the value that determines the resistance of all the circuit connected between the emitter and the collector of the upper IGBT-transistor.

2. The transition process within one positive (anodic) impulse is a damped harmonic oscillation. It is explained by the fact that the complete circuit of the load of the upper IGBT transistor is a successive oscillating circuit with losses; it is well illustrated by the time diagrams shown in Fig. 5.

3. The average and peak heights of the anode impulses of voltage and current depend on the ballast resistance.

4. The maximum values of the cathode impulses of voltage do not depend on the ballast resistance, unlike the peak values of the cathode current impulses.

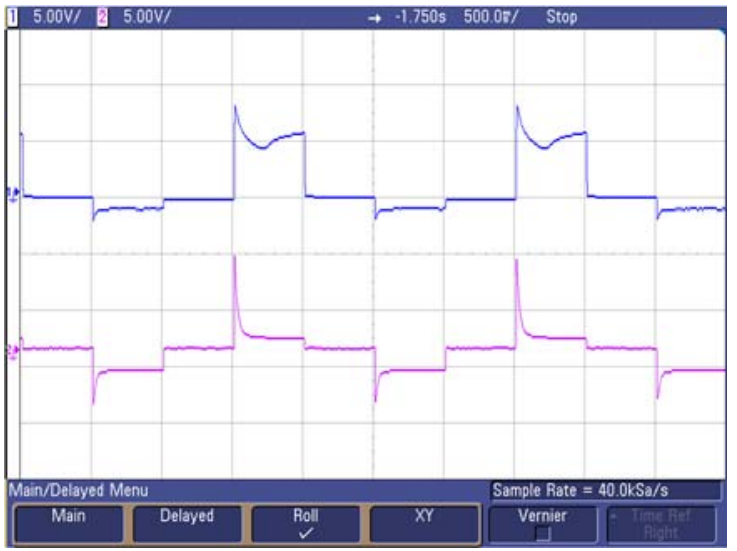

a

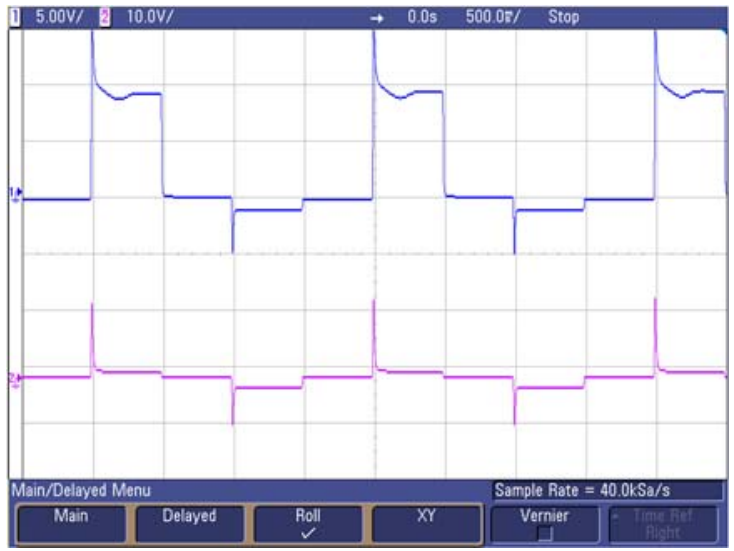

b

Figure 5. Time diagrams of voltages and current on the section "anode - cathode" of the experimental block after the completion of the transition process of MAO: $\mathrm{a}$ - variant $2 ; \mathrm{b}$ - variant 6

Table 1 gives the values of the properties of the switching processes in impulse AC mode of MAO after the completion of the transition process at using six ballast bi-poles, the parameters of which have been given before.

Table 1. The properties of the switching processes in impulse AC mode of MAO

\begin{tabular}{|c|c|c|c|c|c|c|c|}
\hline № & $\mathrm{L}, \mu \mathrm{H}$ & $\mathrm{R}, \mathrm{Om}$ & $\tau, \mathrm{s}$ & $\mathrm{U}_{0}, \mathrm{~V}$ & $\mathrm{U}_{\text {п, }}, \mathrm{V}$ & $\mathrm{I}_{\mathrm{a}}, \mathrm{A}$ & $\mathrm{I}_{\mathrm{c}}, \mathrm{A}$ \\
\hline 1. & 155 & 6,0 & 30 & 120 & 140 & 17 & 12.5 \\
\hline 2. & 446 & 13,7 & 35 & 50 & 80 & 17 & 9.5 \\
\hline 3. & 950 & 0,13 & 35 & 90 & 135 & 27 & 14.5 \\
\hline 4. & 1000 & 30,0 & 40 & 65 & 75 & 7 & 4.5 \\
\hline 5. & 2500 & 0,35 & 40 & 90 & 150 & 28 & 16 \\
\hline 6. & 2500 & 0,35 & 45 & 110 & 125 & 25 & 14 \\
\hline
\end{tabular}

Table 1 contains the following symbols: $\tau$ is the duration of the transition process of $M A O ; \mathrm{U}_{0}$ is the average value of the height of the anode impulses; $U_{\text {п }}$ is the peak value of the height of the anode voltage impulses; $I_{a}$ is the peak value of the height of the anodic current impulses; $I_{C}, A$ is the peak height of the cathodes current impulses.

The values presented in the table show that changing only one parameter of the ballast resistance does not allow reducing the peak values of the voltages and currents on the section "anode - cathode" under impulse AC MAO. It is necessary to determine the values of the inductance and resistance of the ballast resistor considering the maximum parameters of IGBT-transistors and the required parameters of the coating. 


\section{Conclusions}

The principal research results are:

- considering the peculiarities of the execution of the micro-arc oxidation and the peculiarities of the IGBT transistors performance as current regulators, the experimental block has been designed;

- the experimental block allows performing the MAO in impulse AC mode and adjust its parameters;

- the necessity of using ballast resistors to protect the IGBT transistors at performing MAO in impulse AC mode is demonstrated;

- the peculiarities of the switching processes at the IGBT-transistor on the oxidized detail, immersed in the electrolyte, are investigated;

- to reduce the peak values of the voltages and the current in the section "anode - cathode", the inductance of the ballast resistor must be of some hundreds $\mu \mathrm{H}$ and the resistance - of a few Ohms.

\section{Acknowledgements}

This paper has been published within the research project "Research on impact of variable resistance environment on current in IGBT transistors at a non-linear load" was carried out within grant program by European Regional Development Fund for general industrial research and for projects dealing with new product and technology developments. Latvian Investment and development agency Contract number: L-KC-11-0006 project number: KC/2.1.2.1.1/10/01/005

\section{References}

1. Gordienko, P., Dostovalov, I., Zhevtun I., Shabalin, I. (2013) Micro-arc oxidation for pulse polarization in galvanic-dynamical mode. Electronic Processing of Materials, 49(4), p.35-42 (in Russian).

2. Martinenko, V., Muskatjev, V., Chibirkin, V. (2004) New constructions of IGBT modules for highvoltage applications. HiT: Design in Electronics, № 4. p.1-4 (in Russian).

3. Nikitin, A. (2010) Modern high-voltage drivers for IGBT and MOSFET transistors. News of Electronics, № 6. p. 32 - 36 (in Russian).

4. Suminov, I., Belkin, P., Epelfeild, A., Ljudin, V., Krit, B., Borisov, A. (2011) Plasma Electrolytic modification of the metal and alloys surface. Moscow, Technosphera, 464 pp. (in Russian).

5. Suminov, I., Epelfeild, A., Ljudin, V., Krit, B., Borisov, A. (2005) Micro-arc oxidation (theory, technology, equipment), Moscow, ECOMET, 368 pp. (in Russian). 